\title{
Editorial
}

\section{The Risks and Benefits of Antidepressants to Treat Pediatric-Onset Depression and Anxiety Disorders: A Developmental Perspective}

\author{
James F. Leckman \\ Child Study Center, Yale University, New Haven, Conn., USA
}

The use of antidepressants to treat children and adolescents with depression or anxiety disorders is widespread, particularly in the USA $[1,2]$, and is a continuing source of controversy and concern [3-5]. The systematic review by Offidani et al. [6] provides a sobering and compelling reminder that the use of these agents in children and adolescents is associated with a substantial risk of adverse effects (AEs) characterized by excessive emotional arousal or behavioral activation including mania and hypomania [7-10]. Based on data from more than 6,000 subjects gleaned from antidepressant trials in juvenile depressive $(n=17)$ and anxiety disorders $(n=25)$, they documented that at least $10 \%$ of these children and adolescents with either a primary depressive or anxiety disorder experienced AEs characterized by excessive arousal activation. These rates were 3 to 10 times higher than observed during treatment with placebo. Cases of 'mania or hypomania' were reported in $8 \%$ of the children and adolescents on antidepressants compared to just $0.17 \%$ of those treated with placebo.

Despite the many limitations to this systematic review, the message from the authors is clear. We must be vigilant. We must encourage child and adolescent psychiatrists and other practitioners (pediatricians and primary care professionals), at minimum, to be cautious in the prescribing of selective serotonin-reuptake inhibitors (SSRIs) to children and adolescents [3-5]. Patients need

\section{KARGER}

www.karger.com/pps
E-Mail karger@karger.com to be screened for indications of bipolarity and their family histories should be screened for similar features.

Caution is warranted also because antidepressants given to children and adolescents are associated with increased rates of suicidal ideation [11-13] and AEs characterized by excessive emotional arousal or behavioral activation. This realization led the US Food and Drug Administration, as well as British and European regulators, to issue a Public Health Advisory in 2004 announcing a multi-pronged strategy to warn the public about the increased risk of suicidal thoughts and behavior ('suicidality') in children and adolescents being treated with antidepressant medications [3].

Consequently, a frank and open discussion with family members and other involved healthcare providers concerning the risks and benefits of prescribing antidepressants in childhood is needed. Practitioners and families need to consider all treatment modalities, including nonpharmacologic interventions like cognitive-behavioral therapy (CBT) $[4,14]$. This may be particularly true for young children with depressive symptoms. For example, Bridge et al. [11], in a meta-analysis of pediatric antidepressant treatment involving data from nearly 6,000 children and adolescents, were unable to detect a pooled risk difference in response greater than zero in children younger than the age of 12 years treated for major depressive disorder with SSRIs; this was, in part, due
(C) 2013 S. Karger AG, Basel

0033-3190/13/0823-0129\$38.00/0 
to a high rate of placebo response. Specifically, across the 5 trials for which age-grouped data were available, the placebo response rate was $58 \%$ for children under the age of 12 versus a $65 \%$ response rate for those randomly assigned to active medication. Only one agent, fluoxetine, outperformed placebo in depressed children within this age group. Evidence in support of the use of antidepressants to treat pediatric depression disorders is also compromised by the serious challenges which have been raised concerning the accuracy of at least one of the major trials that included 275 adolescents; in this instance, Keller et al. [15] reported that paroxetine was 'generally well tolerated and effective for [the treatment] of major depression in adolescents'. In fact, the study found no significant benefit for either of the two specified primary outcome measures [16, 17]. This is the same clinical trial that led GlaxoSmithKline to plead guilty to criminal charges for promoting paroxetine for use in the pediatric age-range for the treatment of depression http://www. justice.gov/opa/documents/gsk/us-complaint.pdf. Even meta-analyses may be crafted in a fashion to serve the interests of the pharmaceutical industry [18].

The situation for pediatric-onset anxiety disorders is somewhat brighter [19], with the available evidence indicating that SSRIs can provide treatment that is beneficial. Here too, however, the degree of benefit is less than we might hope. For example, in the sample of 488 youths with anxiety disorders that participated in the Child/Adolescent Anxiety Multimodal Study (CAMS) [20], the remission rates after 12 weeks of treatment ranged from 46 to $68 \%$ for combined treatment of sertraline plus CBT, 34 to $46 \%$ for sertraline, 20 to $46 \%$ for CBT and 15 to $27 \%$ for placebo [21]. Consequently, for the majority of children and adolescents randomized to active treatment in the CAMS, significant anxiety symptoms persisted, even among those showing improvement after 12 weeks of treatment. Longer-term outcomes are not well documented. At present, the state-of-the-art is the ongoing Child/Adolescent Anxiety Multimodal Extended LongTerm Study (CAMELS) in which investigators from six sites have been funded to examine, over 5 years, the longterm psychiatric, physical and functional outcomes of the children that participated in the CAMS. Useful data will emerge, but unfortunately, the CAMELS may not provide many of the answers needed. The 488 youths that were randomized in CAMS were a highly selected subset of the 3,066 youths that were initially screened. Consequently, the likelihood is great that many of the children screened also received pharmacotherapy or other interventions, but their long-term outcomes will not have been tracked.
Next, it is also clear that we do not fully comprehend the risks associated with the use of antidepressants at specific developmental stages or the possible long-term adverse consequences of exposure to antidepressants for the developing brain. We are also unclear about why there are differences in the risks and benefits of these agents during development. If a decision to begin antidepressant treatment is made, patients need to be monitored closely by practitioners and their families for a minimum of several months after initiating the therapy [22]. This monitoring needs to include careful and structured questioning concerning possible side effects. Checklists and reliance on self- and parent-reports are not sufficient. Long-term, longitudinal studies that track therapeutic events and AEs over time and that relate these outcomes to different stages of development are needed [19]. Population-based, long-term, follow-up studies using national registry data may address some of these needs [23].

Despite their many limitations, animal studies also have the potential to inform clinical practice [24]. That said, there are a growing number of rodent studies that call into question the long-term safety of antidepressants and their potential for adversely affecting the developing brains of our patients [25-29].

Looking to the future, it is clear that we might well benefit from the development of new psychotropic agents, but the pharmaceutical industry has become cautious for good reason. More importantly, we need to ensure that adequate numbers of child mental-health professionals are trained to deliver CBT. We also need to develop and sustain efforts to build on the strengths and interests of children and adolescents with behavioral and emotional difficulties, and find ways to take advantage of advances in developmental neuroscience in order to enhance the cognitive and emotional development of children with, or at high-risk of developing behavioral and emotional disorders [30].

\section{References} Janhsen K, Fegert JM, Gardner JF, Glaeske G, Valluri SC: A three-country comparison of psychotropic medication prevalence in youth. Child Adolesc Psychiatry Ment Health 2008;2:26.

-2 Pratt LA, Brody DJ, Gu Q. Antidepressant use in persons aged 12 and over: United States, 2005-2008. NCHS Data Brief 2011;76:1-8.

3 Food and Drug Administration Public Health Advisory, October 15, 2004: Suicidality in Children and Adolescents Being Treated with Antidepressant Medication. http:// www.fda.gov/NewsEvents/Newsroom/ PressAnnouncements/2004/ucm108363.htm 
-4 Leckman JF, King RA: A developmental perspective on the controversy surrounding the use of SSRIs to treat pediatric depression. Am J Psychiatry 2007; 164:1304-1306.

5 Adegbite-Adeniyi C, Gron B, Rowles BM, Demeter CA, Findling RL: An update on antidepressant use and suicidality in pediatric depression. Expert Opin Pharmacother 2012;13:2119-303.

6 Offidani E, Fava GA, Tomba E, Baldessarini RJ: Excessive mood-elevation and behavioral activation with antidepressant treatment of juvenile depressive and anxiety disorders: systematic review. Psychother Psychosom, in press.

7 Martin A, Young C, Leckman JF, Mukonoweshuro C, Rosenheck R, Leslie D: Age effects on antidepressant-induced manic conversion. Arch Pediatr Adolesc Med 2004;158: 773-780.

8 Ernst CL, Goldberg JF: Clinical features related to age at onset in bipolar disorder. J Affect Disord 2004;82:21-27.

-9 Reichart CG, Nolen WA: Earlier onset of bipolar disorder in children by antidepressants or stimulants? An hypothesis. J Affect Disor 2004;78:81-84.

-10 Lim CJ, Leckman JF, Young C, Martin A: Antidepressant-induced manic conversion: developmentally informed synthesis of the literature. Int Rev Neurobiol 2005;65:25-52.

-11 Bridge JA, Iyengar S, Salary CB, Barbe RP, Birmaher B, Pincus HA, Ren L, Brent DA: Clinical response and risk for reported suicidal ideation and suicide attempts in pediatric antidepressant treatment: a meta-analysis of randomized controlled trials. JAMA 2007;297:1683-1696.

$\checkmark 12$ Olfson M, Marcus SC, Shaffer D: Antidepressant drug therapy and suicide in severely depressed children and adults: a case-control study. Arch Gen Psychiatry 2006;63: 865-872.

13 Gibbons RD, Hur K, Bhaumik DK, Mann JJ: The relationship between antidepressant prescription rates and rate of early adolescent suicide. Am J Psychiatry 2006;163: 1898-1904.
14 Soeteman DI, Miller M, Kim JJ: Modeling the risks and benefits of depression treatment for children and young adults. Value Health 2012;15:724-729.

15 Keller MB, Ryan ND, Strober M, Klein RG, Kutcher SP, Birmaher B, Hagino OR, Koplewicz H, Carlson GA, Clarke GN, Emslie GJ, Feinberg D, Geller B, Kusumakar V, Papatheodorou G, Sack WH, Sweeney M, Wagner KD, Weller EB, Winters NC, Oakes R, McCafferty JP: Efficacy of paroxetine in the treatment of adolescent major depression: a randomized, controlled trial. J Am Acad Child Adolesc Psychiatry 2001;40:762-772.

16 Jureidini JN, McHenry LB: Key opinion leaders and pediatric antidepressant overprescribing. Psychother Psychosom 2009;78: 197-201.

17 Jureidini JN, McHenry LB: Conflicted medical journals and the failure of trust. Account Res 2011;18:45-54.

18 Fava GA: Meta-analyses and conflict of interest. CNS Drugs 2012;26:93-96.

19 Correll CU, Kratochvil CJ, March JS: Developments in pediatric psychopharmacology: focus on stimulants, antidepressants, and antipsychotics. J Clin Psychiatry 2011;72: 655-670.

20 Walkup JT, Albano AM, Piacentini J, Birmaher B, Compton SN, Sherrill JT, Ginsburg GS, Rynn MA, McCracken J, Waslick B, Iyengar S, March JS, Kendall PC: Cognitive behavioral therapy, sertraline, or a combination in childhood anxiety. N Engl J Med 2008;359:2753-2766.

21 Ginsburg GS, Kendall PC, Sakolsky D, Compton SN, Piacentini J, Albano AM, Walkup JT, Sherrill J, Coffey KA, Rynn MA, Keeton CP, McCracken JT, Bergman L, Iyengar S, Birmaher B, March J: Remission after acute treatment in children and adolescents with anxiety disorders: findings from the CAMS. J Consult Clin Psychol 2011;79:806813.
22 McBee-Strayer S, Gardner W, Kelleher K, Strange B, Heck KM, Fan L: Monitoring pediatric antidepressant use. Behav Healthc 2010;30:19-21.

23 Aagaard L, Thirstrup S, Hansen EH: Opening the white boxes: the licensing documentation of efficacy and safety of psychotropic medicines for children. Pharmacoepidemiol Drug Saf 2009;18:401-411.

24 Andersen SL, Navalta CP: New frontiers in developmental neuropsycho-pharmacology: can long-term therapeutic effects of drugs be optimized through carefully timed interventions? J Child Psychol Psychiatry 2011;52: 477-504.

25 Ansorge MS, Morelli E, Gingrich JA: Inhibition of serotonin but not norepinephrine transport during development produces delayed, persistent perturbations of emotional behaviors in mice. J Neurosci 2008;28:199207.

26 Grzeskowiak LE, Gilbert AL, Morrison JL: Neonatal outcomes after late-gestation exposure to selective serotonin reuptake inhibitors. J Clin Psychopharmacol 2012;32:615621.

27 Salisbury AL, Wisner KL, Pearlstein T, Battle CL, Stroud L, Lester BM: Newborn neurobehavioral patterns are differentially related to prenatal maternal major depressive disorder and serotonin reuptake inhibitor treatment. Depress Anxiety 2011;28:10081019.

28 Pawluski JL, Rayen I, Niessen NA, Kristensen S, van Donkelaar EL, Balthazart J, Steinbusch HW, Charlier TD: Developmental fluoxetine exposure differentially alters central and peripheral measures of the HPA system in adolescent male and female offspring. Neuroscience 2012;220:131-141.

29 Sass A, Wörtwein G: The effect of subchronic fluoxetine treatment on learning and memory in adolescent rats. Behav Brain Res 2012;228:169-175.

30 Leckman JF: What's next for developmental psychiatry? World Psychiatry, in press. 